\title{
Design of dual ligands using excessive pharmacophore query alignment
}

\author{
Daniel Moser*, Joanna Wisniewska, Steffen Hahn, Estel la Buscató, Franca-Maria Klingler, Janosch Achenbach, \\ Bettina Hofmann, Dieter Steinhilber, Ewgenij Proschak
}

From 7th German Conference on Chemoinformatics: 25 CIC-Workshop
Goslar, Germany. 6-8 November 2011

Dual- or multi-target ligands have gained increased attention in the past years due to several advantages, including more simple pharmacokinetic and phamarcodynamic properties compared to a combined application of several drugs. Furthermore multi-target ligands often possess improved efficacy [1]. We present a new approach for the discovery of dual-target ligands using aligned pharmacophore models combined with a shapebased scoring. Starting with two sets of known active compounds for each target, a number of different pharmacophore models is generated and subjected to pairwise graph-based alignment using the Kabsch-Algorithm [2,3]. Since a compound may be able to bind to different targets in different conformations, the algorithm aligns pairs of pharmacophore models sharing the same features which are not necessarily at the exactly same spatial distance. Using the aligned models, a pharmacophore search on a multi-conformation-database is performed to find compounds matching both models. The potentially "dual" ligands are scored by a shape-based comparison with the known active molecules using ShaEP [4].

Using this approach, we performed a prospective fragment-based virtual screening for dual $5-\mathrm{LO} / \mathrm{sEH}$ inhibitors. Both enzymes play an important role in the arachidonic acid cascade and are involved in inflammatory processes, pain, cardiovascular diseases and allergic reactions $[5,6]$. Beside several new selective inhibitors we were able to find a compound inhibiting both enzymes in low micromolar concentrations. The results indicate that the idea of aligned pharmacophore models can be successfully employed for the discovery of dualtarget ligands.

Institute of Pharmaceutical Chemistry, LiFF/OSF/ZAFES, Goethe University, Frankfurt am Main, Germany, Max-von-Laue Str.9, D-60438, Frankfurt/M, Germany
Published: 1 May 2012

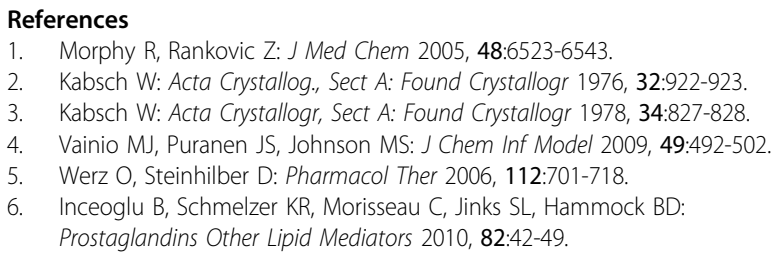

Cite this article as: Moser et al:. Design of dual ligands using excessive pharmacophore query alignment. Journal of Cheminformatics 20124 (Suppl 1):O11.

\section{Publish with ChemistryCentral and every scientist can read your work free of charge \\ "Open access provides opportunities to our colleagues in other parts of the globe, by allowing anyone to view the content free of charge." \\ W. Jeffery Hurst, The Hershey Company. \\ - available free of charge to the entire scientific community \\ - peer reviewed and published immediately upon acceptance \\ - cited in PubMed and archived on PubMed Central \\ - yours - you keep the copyright \\ Submit your manuscript here: \\ http://www.chemistrycentral.com/manuscript/

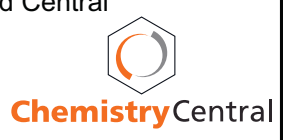

